\title{
Role of Rac1/WAVE2 Signaling in Mediating the Inhibitory Effects of $\gamma$-Tocotrienol on Mammary Cancer Cell Migration and Invasion
}

\author{
Ibrahim Gayadh Algayadh, Venkateshwararao Dronamraju, and Paul William Sylvester* \\ School of Pharmacy, University of Louisiana at Monroe; 700 University Avenue, Monroe LA 71209, U.S.A. \\ Received June 8, 2016; accepted September 12, 2016
}

\begin{abstract}
The majority of breast cancer deaths result from the progression of this disease to a metastatic phenotype. Rac1 and Cdc42 are Rho family members that together with their downstream effectors, Wiskott-Aldrich Syndrome protein-family verprolin-homologous protein 2 (WAVE2) and Arp2/3, play an important role in cytoskeletal reorganization and the formation of membrane protrusions that promote cancer cell migration and invasion. $\gamma$-Tocotrienol, is a natural isoform within the vitamin $E$ family of compounds that inhibits breast cancer cell growth and progression by suppressing various signaling pathways involved in mitogenic signaling and metastatic progression. Studies were conducted to examine the effects of $\gamma$-tocotrienol on Rac1/WAVE2 signaling dependent migration and invasion in highly metastatic mouse +SA and human MDA-MB-231 mammary cancer cells. Exposure to $\gamma$-tocotrienol resulted in a dose-responsive decrease in Rac1/WAVE2 signaling as characterized by a suppression in the levels of Rac1/Cdc42, phospho-Rac1/Cdc42, WAVE2, Arp2, and Arp3 expression. Additional studies also demonstrated that similar treatment with $\gamma$-tocotrienol resulted in a significant reduction in tumor cell migration and invasion. Taken together, these findings indicate that $\gamma$-tocotrienol treatment effectively inhibits Rac1/WAVE2 signaling and reduces metastatic phenotypic expression in mammary cancer cells, suggesting that $\gamma$-tocotrienol may provide some benefit as a novel therapeutic approach in the treatment of metastatic breast cancer.
\end{abstract}

Key words $\gamma$-tocotrienol; breast cancer; Rac1; Wiskott-Aldrich Syndrome protein-family verprolin-homologous protein 2 (WAVE2); migration; invasion

Breast cancer is the most common form of cancer in women and is second only to lung cancer as a leading cause of cancer mortality in the United States. ${ }^{1,2}$ The vast majority of breast cancer deaths result from the development and progression of the metastatic form of this disease, that is characterized by cancer cells detaching from the primary tumor and spreading to distant sites in the body such as the bone, brain, surrounding lymph nodes, liver, and lungs. ${ }^{3-5)}$ Breast cancer metastasis is a complex and multistep process that includes morphological changes, detachment from the basement membrane, increased mobility and invasion into surrounding tissues, intravasation, circulation, adhesion, extravasation, and growth at distant sites. ${ }^{6}$ Since patient prognosis for metastatic breast cancer is very poor, there is great interest in developing antiinvasion therapies to improve patient treatment and survival. ${ }^{7}$ )

An initial step in the metastasis process involves epithelialto-mesenchymal transition (EMT), where neoplastic epithelial cells lose their cellular polarity and acquire mesenchymal-like mobility that allows them to invade surrounding tissues. ${ }^{8-11)}$ This amoeboid-like movement requires the formation of cellular protrusions that result from the conversion of monomeric globular actin (G-actin) to polymerized filamentous actin (Factin). ${ }^{12-15)}$

The Rho family of small G-proteins are members within the Ras superfamily that play an important role in metastasis by enhancing tumor cell motility and invasion. ${ }^{16)}$ Specifically, Racl and $\mathrm{Cdc} 42$ are Rho family members that act to modulate cytoskeletal reorganization by activating actin polymerization. Wiskott-Aldrich Syndrome protein-family verprolinhomologous protein 2 (WAVE2) and the Arp2/3 complex are downstream effectors of $\mathrm{Rac} 1 / \mathrm{Cdc} 42$ that induce the formation of membrane protrusions and ruffles that are required for tumor cell movement. ${ }^{17-20)}$ There are several members within the WAVE family of proteins, but WAVE2 has been shown to be the most important regulating actin polymerization, lamellipodia formation and mesenchymal-like mobility in various cancer cell types. ${ }^{21-24)}$

Previous studies have demonstrated that $\gamma$-tocotrienol, a natural isoform within the vitamin E family of compounds, is a potent anticancer agent that inhibits cancer cell growth and metastasis by inhibiting mitogenic signaling and EMT. ${ }^{25-29)}$ In the present study, experiments were conducted to examine the effects of $\gamma$-tocotrienol on Rac1/WAVE2 signaling and subsequent migration and invasion in the highly metastatic mouse +SA and human MDA-MB-231 mammary tumor cells in vitro.

\section{MATERIALS AND METHODS}

Reagents and Antibodies Chemicals and reagents were obtained from Sigma-Aldrich (St. Louis, MO, U.S.A.), unless stated otherwise. Purified $\gamma$-tocotrienol was generously provided by First Tech International Ltd. (Hong Kong). Antibody for actin was purchased from Santa Cruz biotechnology (Dallas, TX, U.S.A.). Goat anti-rabbit secondary antibody (Ab) was purchased from PerkinElmer, Inc. Biosciences (Boston, MA, U.S.A.). Cultrex ${ }^{\circledR}$ BME Cell Invasion Assay Kit was purchased from Trevigen (Gaithersburg, MD, U.S.A.).

Cell Lines and Culture Conditions The +SA cell is a highly malignant mammary epithelial cell line that was originally isolated from a mammary adenocarcinoma that had developed spontaneously in a BALB/c female mouse. ${ }^{30-32)}$ The CL-S1 cell is an immortalized normal mouse mammary epithelial cell line that was derived from the hyperplastic 
nodule isolated from a BALB/c mouse and do not form solid tumors when implanted back into syngeneic mice. ${ }^{30,33)}+\mathrm{SA}$ and CL-S1 cells were maintained in serum-free defined media consisting of Dulbecco's modified Eagle's medium: nutrient mixture F-12 (DMEM/F12) containing $5 \mathrm{mg} / \mathrm{mL}$ bovine serum albumin (BSA), $10 \mu \mathrm{g} / \mathrm{mL}$ transferrin, $100 \mathrm{U} / \mathrm{mL}$ soybean trypsin inhibitor, $100 \mathrm{U} / \mathrm{mL}$ penicillin, $0.1 \mathrm{mg} / \mathrm{mL}$ streptomycin, $10 \mathrm{ng} / \mathrm{mL}$ epidermal growth factor (EGF), and $10 \mu \mathrm{g} / \mathrm{mL}$ insulin. The human MDA-MB-231 malignant breast cancer cells and normal MCF-10A mammary epithelial cells were purchased from American Type Culture Collection (Manassas, VA, U.S.A.). MDA-MB-231 mammary cancer cells were cultured in RPMI-1640 supplemented with $10 \%$ fetal bovine serum and supplemented with $100 \mathrm{U} / \mathrm{mL}$ penicillin, $0.1 \mathrm{mg} /$ $\mathrm{mL}$ streptomycin, and $10 \mu \mathrm{g} / \mathrm{mL}$ insulin, whereas MCF-10A cells were maintained in DMEM/F12 supplemented with 5\% horse serum, $0.5 \mu \mathrm{g} / \mathrm{mL}$ hydrocortisone, $20 \mathrm{ng} / \mathrm{mL}$ EGF, $100 \mathrm{U} /$ $\mathrm{mL}$ penicillin, $0.1 \mathrm{mg} / \mathrm{mL}$ streptomycin, and $10 \mu \mathrm{g} / \mathrm{mL}$ insulin. All normal and malignant mammary epithelial cell lines were maintained at $37^{\circ} \mathrm{C}$ in a humidified incubator supplied with $95 \%$ air and $5 \% \mathrm{CO}_{2}$. For use in experimentation, cells were isolated and collected for stock culture by first rinsing them in sterile $\mathrm{Ca}^{2+}$ and $\mathrm{Mg}^{2+}$-free phosphate-buffered saline (PBS) and then incubating cells in $0.05 \%$ trypsin containing $0.025 \%$ ethylenediaminetetraacetic acid (EDTA) in PBS for $5 \mathrm{~min}$ at $37^{\circ} \mathrm{C}$. Cells were then collected by centrifugation and then resuspended in medium and counted manually using a hemocytometer.

A

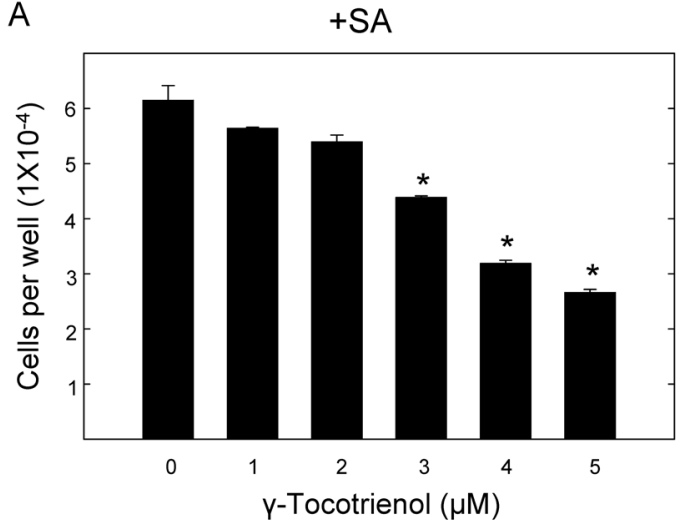

C

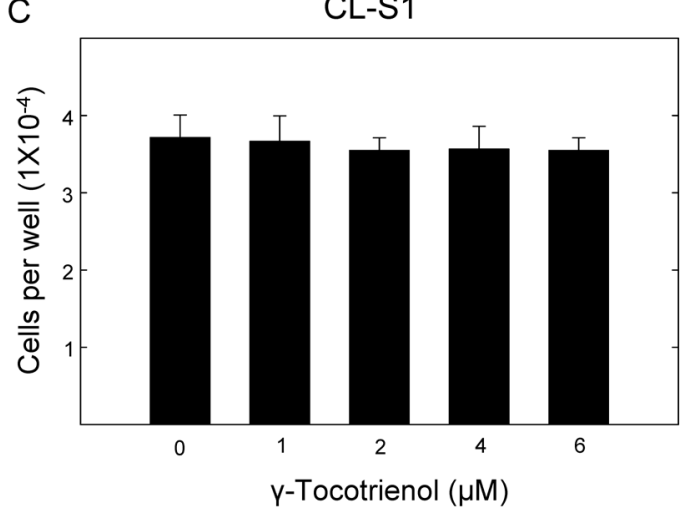

Experimental Treatments The highly lipophilic $\gamma$-tocotrienol was first dissolved in absolute ethanol and then added to sterile $10 \% \mathrm{BSA}$ in water and incubated at $37^{\circ} \mathrm{C}$ overnight with gentle shaking as described previously. ${ }^{34,35)}$ This stock $\gamma$-tocotrienol solution was then used to prepare different concentrations of treatment media.

Measurement of Viable Cell Number For cell growth studies, (+SA, CL-S1, MDA-MB-231 and MCF-10A) cells were seeded at a density of $1 \times 10^{4}$ cells/well in 96-well culture plates (6 replicates/group). The following day, cells were divided into various treatment groups and exposed to $0-20 \mu \mathrm{M}$ $\gamma$-tocotrienol. Cells were fed fresh treatment media every other day for $4 \mathrm{~d}$. For cytotoxicity studies, (+SA, MDA-MB-231, CL-S1, and MCF-10A) cells were seeded at a density of $1 \times 10^{4}$ cells/well in 96-well culture plates (6 replicates/group), fed control media and allowed to growth for a 3-d period (approximately $70 \%$ confluent). Cells were then divided into various treatment groups and treated with $0-60 \mu \mathrm{M} \gamma$-tocotrienol for an acute $24-\mathrm{h}$ culture period. The next day, viable cell count was determined using 3-(4,5-dimethylthiazol-2-yl)-2,5diphenyltetrazolium bromide (MTT) colorimetric assay as described previously. ${ }^{34,35)}$ Briefly, cells were incubated at $37^{\circ} \mathrm{C}$ for $3 \mathrm{~h}$ in control media containing $0.5 \mathrm{mg} / \mathrm{mL}$ MTT. Afterwards, media was removed and MTT crystals dissolved in dimethyl sulfoxide (DMSO; $100 \mu \mathrm{L} /$ well), and optical density of each sample was measured at $570 \mathrm{~nm}$ on a microplate reader (SpectraCount, Packard BioScience Company, Meriden, CT, U.S.A.). The number of cells/well was calculated against a
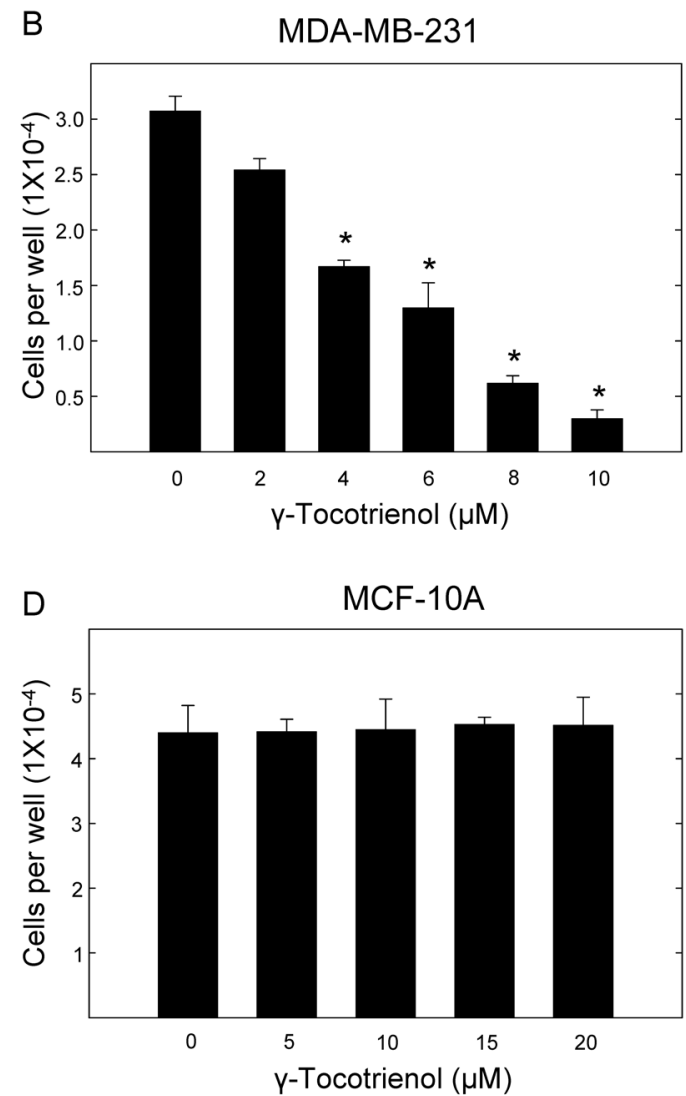

Fig. 1. Growth Inhibitory Effects of $\gamma$-Tocotrienol on Highly Malignant +SA (A) and MDA-MB-231 (B), and Immortalized Normal CL-S1 (C) and MCF-10A (D) Mammary Epithelial Cells

All cells were initially plated at a density of $1 \times 10^{4}$ cells/well (6 wells/group) in 96 -well plates. Cells were allowed to attach for a $24 \mathrm{~h}$ period and then subjected to their specific treatments for a 4-d culture period. The MTT colorimetric assay was used to count viable cell number. Vertical bars indicate the mean cell number \pm S.E.M. in each treatment group. ${ }^{*} p<0.05$ as compared with their respective vehicle-treated control group. 
standard curve prepared by plating known cell densities at the start of experimentation.

Western Blot Analysis MDA-MB-231 and +SA cells were initially plated at $1 \times 10^{6}$ cells $/ 100 \mathrm{~mm}$ culture plate. The next day, cells were fed their respective treatment media containing $0-6 \mu \mathrm{M} \gamma$-tocotrienol for a 4 -d culture period. Afterwards, cells were washed with PBS, trypsin was used to isolate cells and lysates were collected for later assay. ${ }^{35)}$ The Bio-Rad protein assay kit (Bio-Rad, Hercules, CA, U.S.A.) was used to determine protein concentration in each sample. Equal amounts were loaded into each well and then electrophoresis through sodium dodecyl sulfate (SDS)polyacrylamide minigels was performed. Proteins from each gel were then transferred at $30 \mathrm{~V}$ for $12-16 \mathrm{~h}$ at $4^{\circ} \mathrm{C}$ onto a single polyvinylidene fluoride membrane (Dupont, Boston, MA, U.S.A.). Membranes were then blocked and incubated with specific primary antibodies diluted $1: 1000$ to $1: 5000$ as described previously. ${ }^{35)}$ Membranes were then washed and incubated with their respective horseradish-peroxide conjugated secondary antibodies diluted $1: 5000{ }^{35)}$ Specific protein bands were visualized by chemiluminescence (Pierce, Rockford, IL, U.S.A.). Images of Western blots were acquired using the Syngene Imaging System (Fredrick, MD, U.S.A.). Actin bands were used to ensure equal sample loading in each lane. Scanning densitometric analysis was performed with Kodak Molecular Imaging Software 4.5 (Carestream Health Inc., New Haven, CT, U.S.A.). Experiments were repeated a minimum of 3 times, and representative images are shown in the figures.
Immunocytochemical Fluorescence Staining MDAMB-231 and +SA cells were initially plated at $2 \times 10^{4}$ cells/ chamber in 8-chamber glass (BD Falcon, San Jose, CA, U.S.A.) and maintained in control media. The next day, media was removed, cells washed in PBS and then cells were exposed to their respective treatment media $(0-4 \mu \mathrm{M} \gamma$-tocotrienol) for a 4-d culture period. Afterwards, cells were washed, fixed in $4 \%$ paraformaldehyde/PBS and then permeabilized with $0.2 \%$ triton X-100/PBS as described previously. ${ }^{36)}$ Fixed cells were then washed, blocked with 5\% goat serum, and exposed to the primary $\mathrm{Ab}$ for WAVE2 $(1: 1000)$ at $4^{\circ} \mathrm{C}$ overnight. ${ }^{36)}$ The following day, cells were washed and then incubation with Alexa Flour 488 conjugated secondary $\mathrm{Ab}(1: 5000){ }^{36)}$ Slides were then washed and mounted with Vectashield medium containing 4'-6-diamidino-2-phenylindole (DAPI) (Vector Laboratories Inc., CA, U.S.A.). ${ }^{36)}$ A LSM Pascal confocal microscope (Carl Zeiss Microimaging Inc, Thornwood, NY, U.S.A.) was then used to capture fluorescence images.

Invasion Assay Cancer cell invasion was assessed using the Cultrex ${ }^{\circledR}$ 96-well basement membrane extract (BME) cell invasion assay kit as described in the instructions (Trevigen Inc., Gaithersburg, MD, U.S.A.). Briefly, +SA and MDAMB-231 cells were plated at a density of $1 \times 10^{6}$ cells $/ 100 \mathrm{~mm}$ culture plate and maintained in their respective control media for a 3-d culture period (approximately 70\% confluent). Afterwards, cells were washed in sterile PBS, given serumfree media and starved for a 24-h culture period. The next day cells were isolated with trypsin, washed, counted and
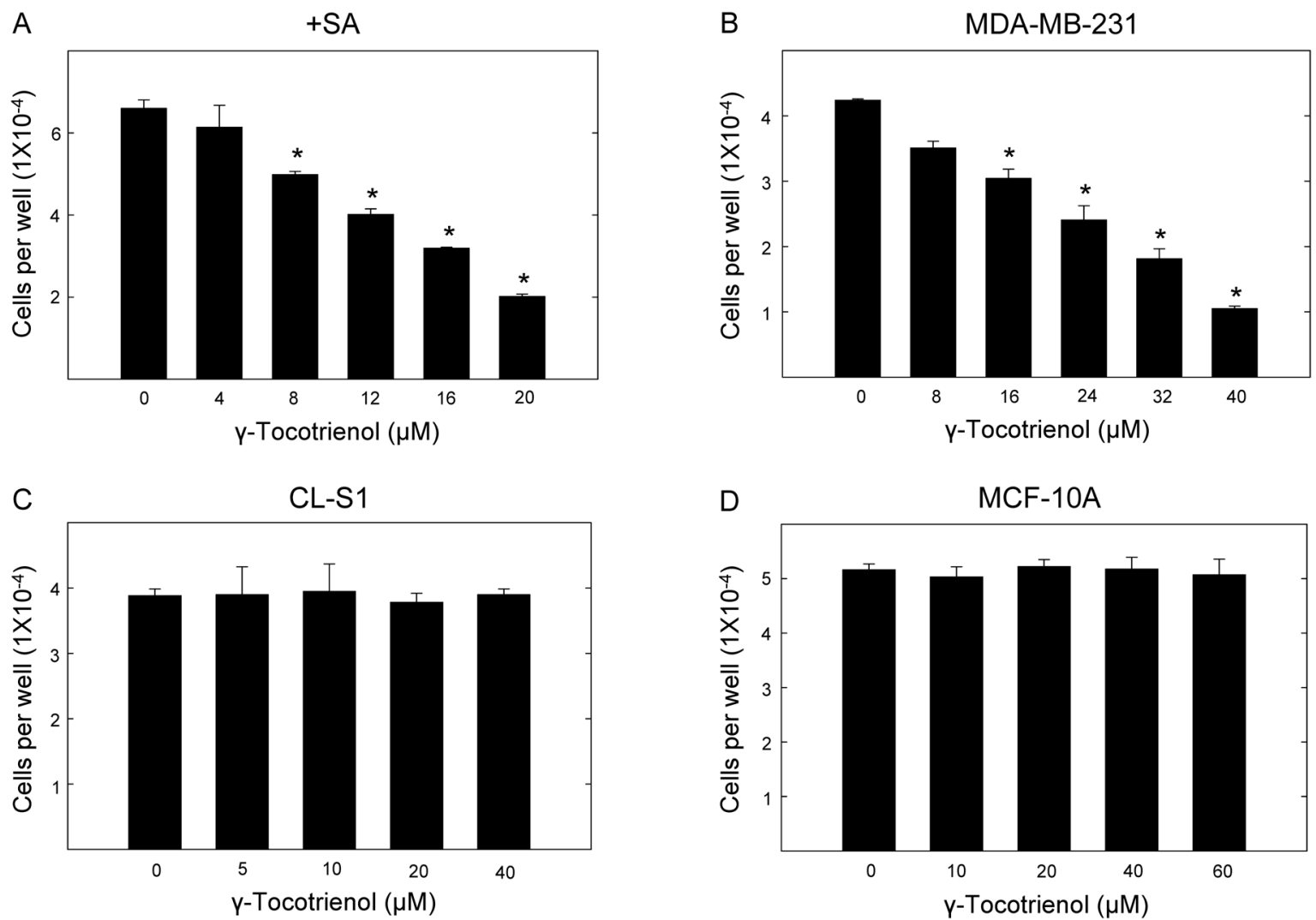

Fig. 2. Cytotoxic Effects of $\gamma$-Tocotrienol on Highly Malignant +SA (A) and MDA-MB-231 (B), and Immortalized Normal CL-S1 (C) and MCF-10A (D) Mammary Epithelial Cells

All cells were initially plated at a density of $1 \times 10^{4}$ cells/well (6 wells/group) in 96 -well plates and maintained on media for a 3 -d culture period (approximately $70 \%$ confluent). Cells were then exposure to their respective treatments for an acute 24 -h culture period. The MTT colorimetric assay was used to count viable cell number. Vertical bars indicate the mean cell number \pm S.E.M. in each treatment group. ${ }^{*} p<0.05$ as compared with their respective vehicle-treated control group. 
(A)

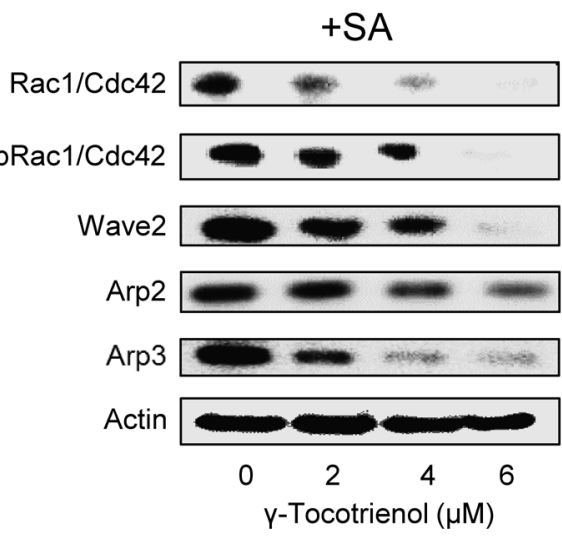

(C)

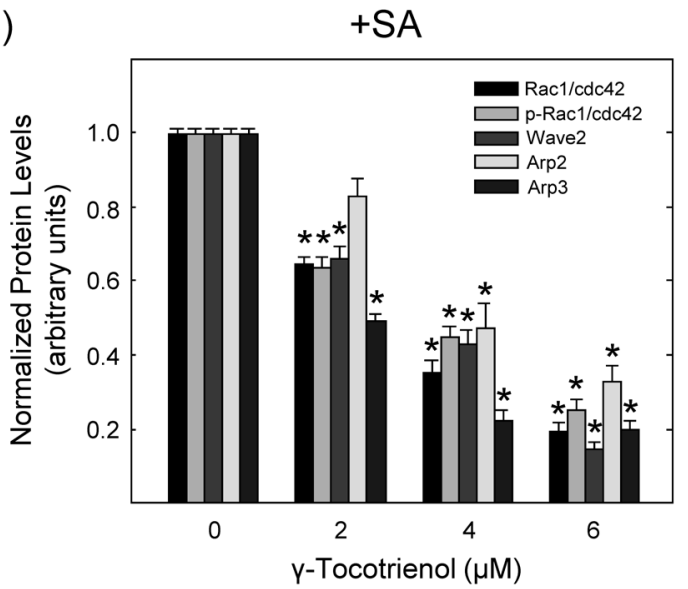

(B)

MDA-MB-231

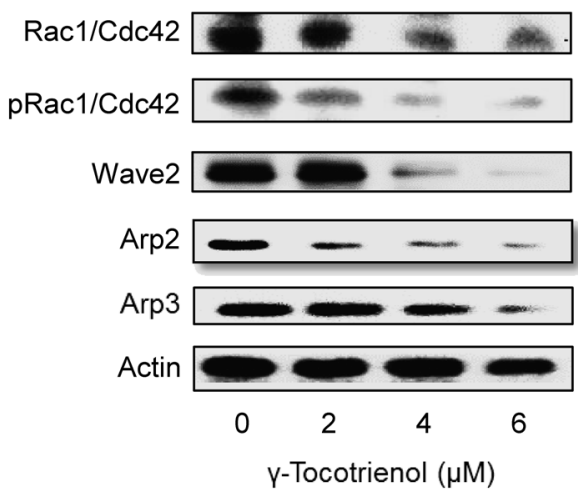

(D)

MDA-MB-231

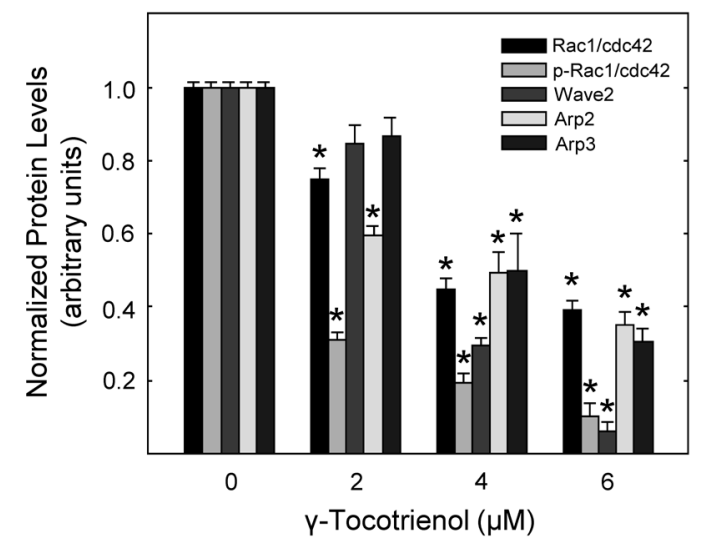

Fig. 3. Western Blot Analysis of $\gamma$-Tocotrienol Effects on Rac1/WAVE2 Signaling Proteins in (A) Mouse +SA and (B) Human Highly Metastatic Mammary Tumor Cells

Cells were initially plated at a density of $1 \times 10^{6}$ cells $/ 100 \mathrm{~mm}$ culture plate and allowed to attach overnight. The next day, cells were exposed their respective treatment containing $0-6 \mu \mathrm{M} \gamma$-tocotrienol for a 4-d culture period. Cells were then isolated with trypsin and whole cell lysates were prepared for subsequent Western blot analysis of Rac1/Cdc42, phospho-Rac1/Cdc42, Wave2, Arp2, and Arp3. Actin bands were visualized to ensure equal sample loading. Western blots are a representative images obtained in experiments that were repeated 3 or more times. Scanning densitometric analysis of each blot are shown in (C) +SA and (D) MDA-MB-231. Integrated optical density (arbitrary units) of each band was normalized with their corresponding actin and control treatment bands. Vertical bars represent the protein levels in individual treatment groups \pm S.E.M. as compared with their respective vehicle-treated control group. ${ }^{*} p<0.05$ as compared with their respective vehicle-treated control group.

$5 \times 10^{4}$ cells/well (5 wells/group) was plated on the top invasion chamber of the 96 -well plate provided in the kit in $50 \mu \mathrm{L}$ of media containing 0 or $4 \mu \mathrm{M} \gamma$-tocotrienol. At the same time, $150 \mu \mathrm{L}$ of that group's respective control or treatment media was placed in the bottom chamber treatment of the plate. After a $24 \mathrm{~h}$ incubation period, the top chamber of cells in each treatment group was then washed, treated with the assay solution for $1 \mathrm{~h}$ and then samples were read at $485 \mathrm{~nm}$ excitation, $520 \mathrm{~nm}$ emission. Fluorescence intensity for each sample was then read against a standard curve to determine percent cell invasion as describe in the instructions provided in the kit.

Migration Assay MDA-MB-231 and +SA cells were plated in 24-well plates (6 replicates/group) and returned to the incubator overnight to form a sub-confluent cell monolayer. Wounds were then made by making a scratch with a sterile $200-\mu \mathrm{L}-$ micropipette tip. Media was then removed, cells washed, and then cells were fed their respective serumfree treatment media containing $0-4 \mu \mathrm{M} \quad \gamma$-tocotrienol and $10 \mathrm{ng} / \mathrm{mL}$ EGF as a mitogen. After a $24 \mathrm{~h}$ incubation period, media was removed, washed in ice-cold PBS, fixed in $-20^{\circ} \mathrm{C}$ methanol, and then stained with Giemsa reagent. Images were visualized using a phase-contrast microscopy (Nikon Eclipse TS100 inverted microscope, Nikon Instruments Inc., Melville,

\section{NY, U.S.A.). ${ }^{37)}$}

Statistical Analysis Differences among treatment groups was determined using one-way ANOVA followed by Dunnett's $t$ test. $p<0.05$ was considered to be statistically significant as compared with their respective control groups.

\section{RESULTS}

Growth Inhibitory Effects of $\gamma$-Tocotrienol on Normal and Neoplastic Mouse and Human Mammary Epithelial Cells After a 4-d treatment period, $\gamma$-tocotrienol induced a dose-responsive inhibition in growth of mouse $(+\mathrm{SA})$ and human (MDA-MB-231) mammary tumors cells as compared to cells in their respective vehicle-treated control groups (Figs. 1A, B). However, treatment with higher doses of $\gamma$-tocotrienol had no effect on immortalized normal mouse (CL-S1) and human (MCF-10A) mammary epithelial cells (Figs. 1C, D). The $\mathrm{IC}_{50}$ dose for $\gamma$-tocotrienol was determined to be 4.3 and $4.4 \mu \mathrm{M}$ for $+\mathrm{SA}$ and MDA-MB-231 mammary tumor cells, respectively.

Acute Cytotoxic Effects of $\gamma$-Tocotrienol on Normal and Neoplastic Mouse and Human Mammary Epithelial Cells After an acute $24 \mathrm{~h}$ treatment exposure, $\gamma$-tocotrienol induced a dose-responsive reduction in viability of $+\mathrm{SA}$ and 
(A)

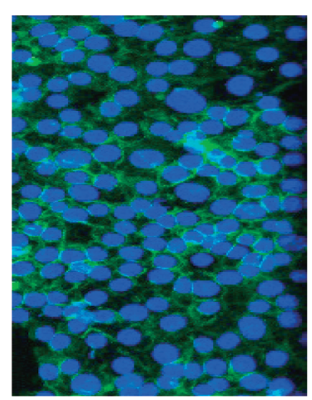

0

(C)
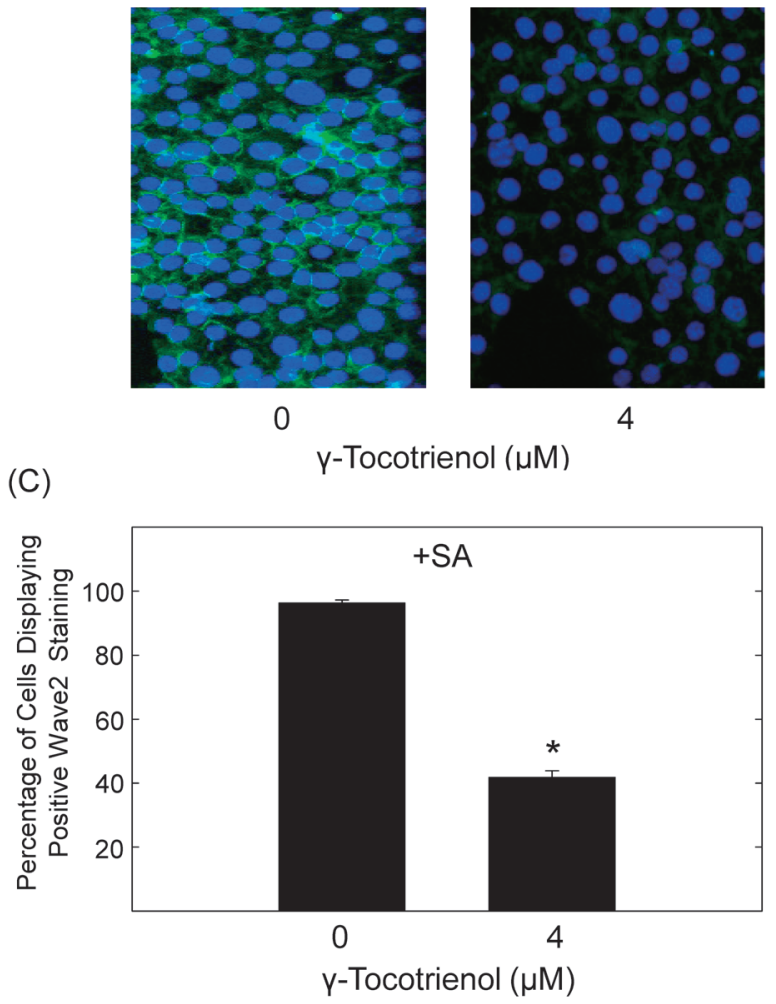

4

$\mathrm{v}$-Tocotrienol ( $\mathrm{MM}$ )
(B)

(D)

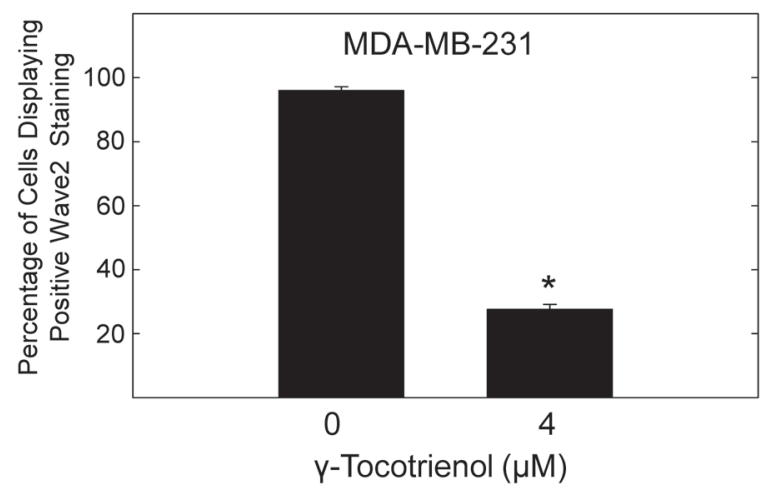

Fig. 4. Effects of $\gamma$-Tocotrienol on WAVE2 Immunofluorescent Staining in Highly Metastatic +SA (A) and MDA-MB-231 (B) Mammary Tumor Cells

Cells were initially plated at a density of $2 \times 10^{4}$ cells/chamber in 8 -chamber glass ( 6 chambers/group) and allowed to attach overnight. Cells were then treated with vehicle or $4 \mu \mathrm{m} \gamma$-tocotrienol for $4 \mathrm{~d}$. Afterwards, cells were fixed, blocked and then incubated with specific primary antibody for WAVE2 followed by incubation with Alexa flour 488 conjugated secondary antibody. Magnification of each image is $200 \times$. The green staining indicates positive staining for WAVE2, while the blue color represents counterstaining of cell nuclei with DAPI. Quantitative image analysis of treatment effects on the percentage of +SA (C) and MDA-MB-231 (D) mammary tumor cells displaying positive WAVE2 staining as compared to the total number of cells within each treatment group. Vertical bars represent the percentage of positive WAVE2 staining cells \pm S.E.M. in each treatment group. $* p<0.05$ as compared with their respective vehicle-treated control group. Cells were counted manually in five photomicrographs selected randomly in each chamber for all treatment groups.
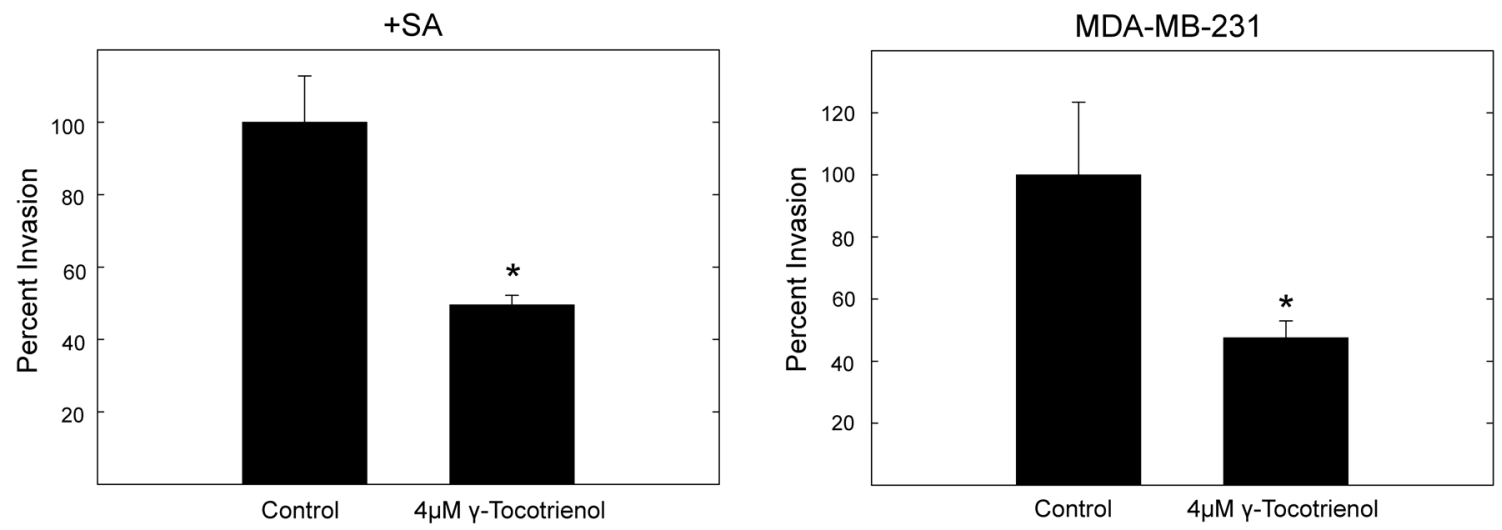

Fig. 5. Effects of $\gamma$-Tocotrienol on + SA and MDA-MB-231 Cell Invasion of Basement Membrane Extract (BME)

Experiment were performed in triplicate. Vertical bar represents the percent invasion \pm S.E.M. $* p<0.05$ as compared with their respective vehicle-treated control group.

MDA-MB-231 mammary tumors cells as compared to cells in their respective vehicle-treated control groups (Figs. 2A, B). Treatment with higher doses of $\gamma$-tocotrienol had little or no effect on viability of immortalized normal mouse (CL-S1) and human (MCF-10A) mammary epithelial cells (Figs. 2C, D). The $\mathrm{LD}_{50}$ dose for $\gamma$-tocotrienol was determined to be 14.7 and $28 \mu \mathrm{M}$ for $+\mathrm{SA}$ and MDA-MB-231 mammary tumor cells, respectively. Based on the results obtained in the antiproliferative (Fig. 1) and cytotoxic (Fig. 2) studies, treatment doses between $0-6 \mu \mathrm{M} \gamma$-tocotrienol was selected for use in subsequent experiments because these doses inhibited cell growth, but were not cytotoxic to both + SA and MDA-MB-231 mammary tumor cells.

Effects of $\gamma$-Tocotrienol on Rac1/WAVE2 Signaling Protein Expression in Mammary Tumor Cells Western blot analysis shows that after a $4-\mathrm{d}$ treatment period with $0-6 \mu \mathrm{M}$ $\gamma$-tocotrienol, +SA and MDA-MB-231 mammary tumor cells displayed a dose-responsive decrease in $\mathrm{Rac1} / \mathrm{Cdc} 42$, phosphoRac1/Cdc42, WAVE2, Arp2, and Arp3, as compared with cells in their respective vehicle-treated control groups (Figs. 3A, B). 
(1)

\section{$24 \mathrm{~h}$ After Treatment}

(A)
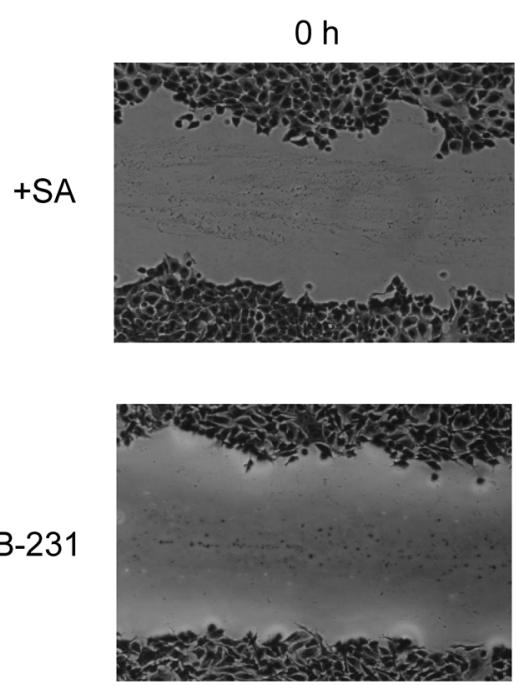
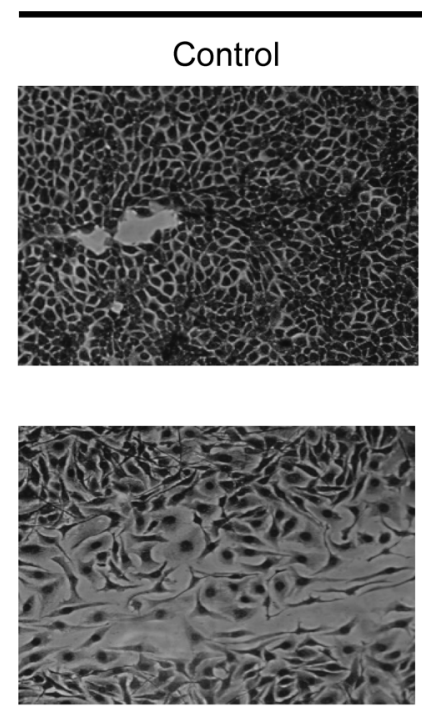
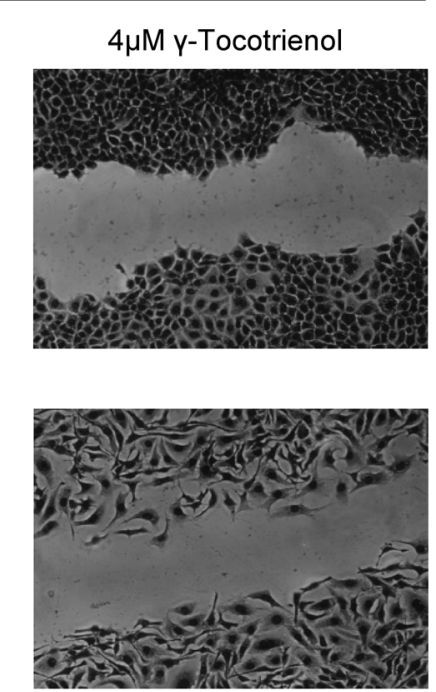

MDA-MB-231

(B)

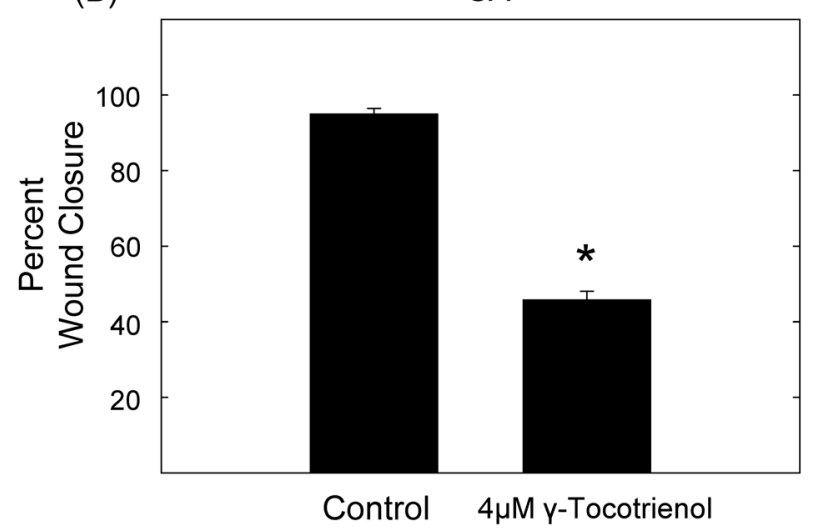

MDA-MB-231

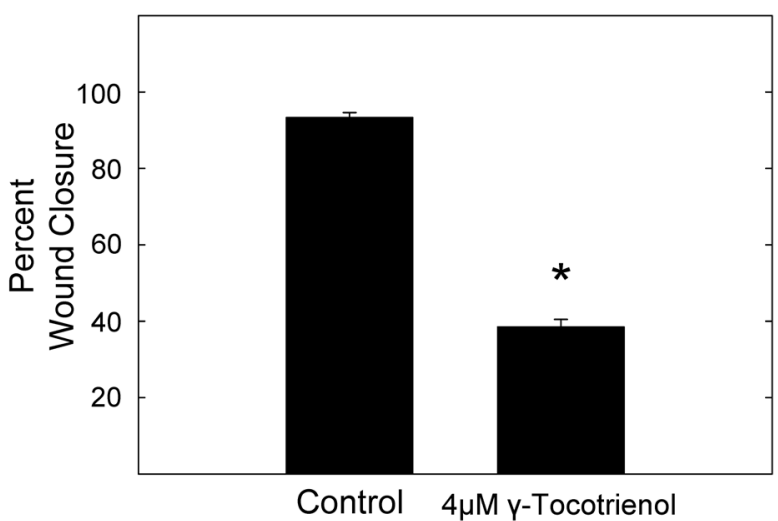

Fig. 6. (A) Effects of $\gamma$-Tocotrienol on the Migration of +SA and MDA-MB-231 Mammary Tumor Cells

Cells were plated in 24-well plates (6 replicates/group) and placed in the incubator overnight in order to form a sub-confluent monolayer in each well. Wounds were then scratched in each well using a sterile $200-\mu \mathrm{L}$-micropipette tip. Cells were then exposed to their respected treatment media for a $24-\mathrm{h}$ culture period. (B) Vertical bars represent the wound closure in each treatment group and as determined relative to the wound distance at the start of the experiment. Each experiment was performed in triplicate and the distance migrated was calculated in three or more randomly selected fields per treatment group. $* p<0.05$ as compared with their respective vehicletreated control group.

Scanning densitometric analysis of Western blots showed that treatment with $4-6 \mu \mathrm{M} \gamma$-tocotrienol significantly decreased Rac1/Cdc42, pRac1/Cdc42, WAVE2, Arp2, and Arp3 levels, as compared with cells in their respective vehicle-treated control groups (Figs. 3C, D).

Effects of $\boldsymbol{\gamma}$-Tocotrienol on WAVE2 Immunofluorescent Staining in Mammary Tumor Cells +SA (Fig. 4A) and MDA-MB-231 (Fig. 4B) cells in their respective vehicletreated control groups displayed a moderate level of positive WAVE2 immunofluorescence staining. Treatment with $4 \mu \mathrm{M}$ $\gamma$-tocotrienol resulted in nearly a complete elimination of positive WAVE2 immunofluorescence staining (Figs. 4A, B). Image analysis of fluorescence photomicrographs showed that treatment with $4 \mu \mathrm{M}$ tocotrienol resulted in a significant decrease in positive WAVE2 staining in both + SA (Fig. 4C) and MDA-MB-231 (Fig. 4D) mammary tumor cells, as compared to cells in their respective vehicle-treated control groups.

Effects of $\boldsymbol{\gamma}$-Tocotrienol on Mammary Tumor Cell Invasion The Cultrex ${ }^{\circledR}$ BME cell invasion assay was used to determine the effects of $\gamma$-tocotrienol on mouse $(+\mathrm{SA})$ and human (MDA-MB-231) breast cancer cell invasion. Results showed that +SA and MDA-MB-231 cells in the vehicletreated control groups displayed nearly complete invasion into the BME, whereas treatment with $4 \mu \mathrm{M} \gamma$-tocotrienol caused an approximate $50 \%$ reduction in $+\mathrm{SA}$ and MDA-MB-231 cell invasion into the BME, as compared to cells in their respective vehicle-treated control groups (Fig. 5).

Effects of $\boldsymbol{\gamma}$-Tocotrienol on Mammary Tumor Cell Migration The wound-healing assay was used to determine the effects of $\gamma$-tocotrienol on mouse (+SA) and human (MDAMB-231) breast cancer cell motility. Results show that cells in the +SA and MDA-MB-231 vehicle-treated control groups displayed nearly complete wound closure, whereas treatment with $4 \mu \mathrm{M} \gamma$-tocotrienol resulted in a large reduction in cell migration after a $24 \mathrm{~h}$ treatment period (Fig. 6A). Quantitative analysis determined that $\gamma$-tocotrienol treatment significantly inhibited breast cancer cell migration by nearly $50 \%$ (+SA) and $56 \%$ (MDA-MB-231), as compared to cell in their respective vehicle-treated control groups (Fig. 6B). 


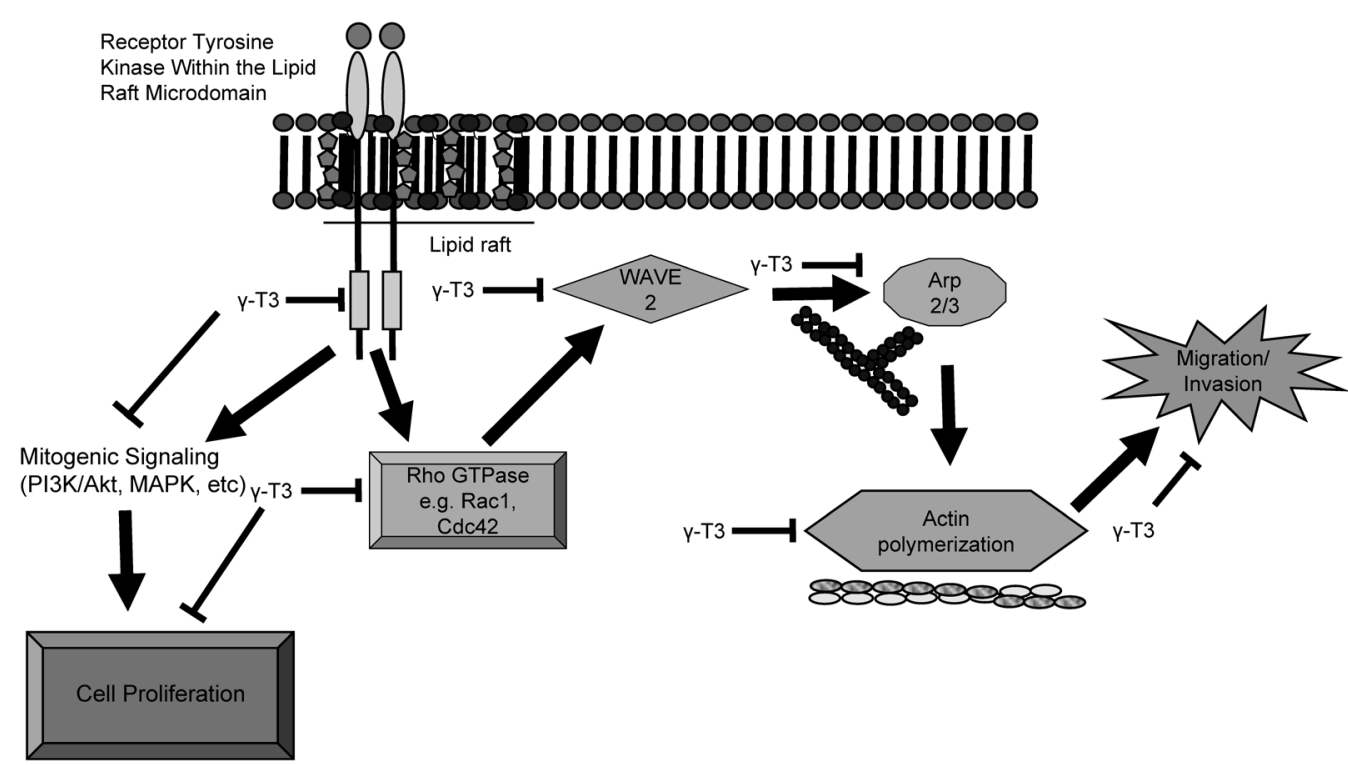

Fig. 7. Schematic Illustration of the Apparent Mechanism(s) Involved in Mediating the Antiproliferative and Anti-metastatic Effects of $\gamma$-Tocotrienol

Previous studies have shown that $\gamma$-tocotrienol disrupts lipid rafts in the plasma membrane and inhibits receptor tyrosine kinase activation and signaling of various mitogenic pathways. Furthermore, $\gamma$-tocotrienol inhibits downstream Rac1/WAVE2 signaling associated with a actin polymerization and results in cytoskeletal changes that suppress cellular mobility and invasion of metastatic breast cancer cells.

\section{DISCUSSION}

Results from these studies demonstrate that treatment with $4 \mu \mathrm{M} \gamma$-tocotrienol induced a significant inhibition in growth of the highly metastatic mouse (+SA) and human (MDAMB-231) mammary tumor cells. However, treatment with higher doses of $\gamma$-tocotrienol had little or no effect on the growth or viability of immortalized normal mouse (CL-S1) and human (MCF-10A) mammary epithelial cells, indicating that cancer cells display a selective sensitivity to the antiproliferative effects of $\gamma$-tocotrienol, as compared to normal, noncancerous cells. The antiproliferative effects of $\gamma$-tocotrienol were associated with a significant reduction in Rac1/WAVE2 signaling as characterized by a suppression in the levels of Rac1/Cdc42, pRac1/Cdc42, WAVE2, Arp2, and Arp3 expression in mammary tumor cells. Additional studies showed that similar treatment with $\gamma$-tocotrienol resulted in a significant reduction in tumor cell migration and invasion. Taken together, these findings indicate that exposure to $\gamma$-tocotrienol effectively inhibits Rac1/WAVE2 signaling and these effects are associated with an attenuation in metastatic phenotype expression in the highly malignant breast cancer cells. A schematic representation of the inhibitory effects of $\gamma$-tocotrienol on Rac1/WAVE2 signaling and resulting reduction in metastatic activity is summarized in Fig. 7.

The anticancer effects of tocotrienols have previously been described in detail. ${ }^{38,39)}$ A great deal of evidence indicates that the anticancer activity of $\gamma$-tocotrienol is mediated, at least in part, by its accumulation and disruption of lipid raft integrity and suppression of receptor activation and signaling. ${ }^{25)}$ Specifically, studies have shown that breast cancer cells exposed to growth inhibiting doses of $\gamma$-tocotrienol display significant inhibition in HER2/ErbB2, HER3/ErbB3, HER4/ErbB4, and c-Met activation, ${ }^{25-27,37,40-42)}$ and their downstream effectors including mitogen-activated protein kinase (MAPK), phosphatidylinositol 3-kinase (PI3K)/Akt, Stat, and nuclear factorkappa $\mathrm{B}(\mathrm{NF} \kappa \mathrm{B}){ }^{35,40,43-45)}$ Furthermore, $\gamma$-tocotrienol suppres- sion of c-Met receptor signaling was directly associated with a suppression in EMT, as evidence by an increased expression of epithelial markers such as E-cadherin, $\beta$-catenin, and cytokeratins $8 / 18$ and corresponding decrease in the expression of vimentin, a mesenchymal marker. ${ }^{26,37)}$

It is now well established that Rac1/WAVE2 signaling plays an important role in promoting EMT and metastasis in a variety of cancer cell types. ${ }^{46-49)}$ Studies have also shown that overexpression of Racl and/or Cdc42 is commonly observed in metastatic breast cancer and is associated with a poor patient prognosis. ${ }^{48,50)}$ WAVE2 and Arp2/3 are the primary downstream effectors for $\mathrm{Racl} / \mathrm{Cdc} 42$, and stimulate actin polymerization, lamellipodia formation and elongation, and mesenchymal-like mobility and migration. ${ }^{17-21,51)}$ Findings in the present study show that $\gamma$-tocotrienol treatment results in a significant and dose-responsive decrease in total and phosphoRac1/Cdc42, and corresponding decrease in WAVE2, Arp2 and Arp3 levels in the highly metastatic +SA and MDAMB-231 breast cancer cells. Immunofluorescence studies confirmed these findings and showed that similar treatment with $\gamma$-tocotrienol resulted in a large reduction in positive WAVE2 staining in these metastatic breast cancer cell lines.

Rac1/WAVE2 dependent actin polymerization is required for cytoskeletal mediated cellular protrusions, membrane ruffling and mobility. ${ }^{13,15)}$ Results showed that $\gamma$-tocotrienolinduced inhibition of Rac1/WAVE2 signaling was associated with a suppression in invasion and mobility. Specifically, $\gamma$-tocotrienol treatment significantly inhibited the invasion of highly malignant + SA and MDA-MB-231 breast cancer cells through a basement membrane matrix. In addition, similar treatment with $\gamma$-tocotrienol significantly inhibited the mobility of these same cells as determined in the wound healing assay. These findings strongly suggest that $\gamma$-tocotrienolinduced inhibitory effects on Rac1/WAVE2 signaling is associated with a suppression in cytoskeletal changes that are related to cellular mobility and invasion in metastatic breast cancer cells. $15,17,18,52)$ 
Previous studies have investigated the role of WAVE proteins in actin polymerization, membrane protrusions and mobility in breast cancer cells. ${ }^{15,17-19,52)}$ Analysis of the three WAVE protein expression in human breast cancer biopsies showed high levels of all WAVE proteins in all breast cancers, but only WAVE2 expression was correlated with a highly metastatic phenotype and poor patient prognosis, whereas elevations in WAVE1 and WAVE3 showed no such correlation. ${ }^{53)}$ Other studies showed that Arp2 and WAVE2 are co-expressed in a high percentage of invasive ductal breast carcinomas, but not in surrounding non-cancerous tissue. ${ }^{51)}$ Furthermore, cellular protrusions required the translocation of WAVE2 to the leading edge of the lamellipodia for Racl dependent migration and invasion of MDA-MB-231 breast cancer cells. ${ }^{54}$ Taken together, findings in the present study provide evidence to suggest that the inhibitory effects of $\gamma$-tocotrienol on malignant + SA and MDA-MB-231 breast cancer cell migration and invasion, appears to be mediated by a suppression in Racl/ WAVE2 signaling, and indicate that $\gamma$-tocotrienol may provide some benefit in the treatment of metastatic breast cancer.

Acknowledgments This work was supported in part by funds provided by the Louisiana Cancer Foundation and the Saudi Arabian Cultural Mission (SACM). The authors would like to thank Dr. Karen P. Briski for use of the laser confocal microscopy.

Conflict of Interest The authors declare no conflict of interest.

\section{REFERENCES}

1) Siegel RL, Miller KD, Jemal A. Cancer statistics, 2015. CA Cancer J. Clin., 65, 5-29 (2015).

2) Taylor MA, Davuluri G, Parvani JG, Schiemann BJ, Wendt MK, Plow EF, Schiemann WP, Sossey-Alaoui K. Upregulated WAVE3 expression is essential for TGF- $\beta$-mediated EMT and metastasis of triple-negative breast cancer cells. Breast Cancer Res. Treat., 142, 341-353 (2013).

3) Escudero-Esparza A, Jiang WG, Martin TA. Claudin-5 is involved in breast cancer cell motility through the N-WASP and ROCK signalling pathways. J. Exp. Clin. Cancer Res., 31, 43 (2012).

4) Ishihara D, Dovas A, Hernandez L, Pozzuto M, Wyckoff J, Segall JE, Condeelis JS, Bresnick AR, Cox D. Wiskott-Aldrich syndrome protein regulates leukocyte-dependent breast cancer metastasis. Cell Reports, 4, 429-436 (2013).

5) Ko HS, Kim JS, Cho SM, Lee H-J, Ahn KS, Kim S-H, Lee E-O. Urokinase-type plasminogen activator expression and Rac1/ WAVE-2/Arp2/3 pathway are blocked by pterostilbene to suppress cell migration and invasion in MDA-MB-231 cells. Bioorg. Med. Chem. Lett., 24, 1176-1179 (2014).

6) Yamaguchi H, Condeelis J. Regulation of the actin cytoskeleton in cancer cell migration and invasion. Biochim. Biophys. Acta (BBA)Molecular Cell Research, 1773, 642-652 (2007).

7) Kim JS, Kang CG, Kim S-H, Lee E-O. Rhapontigenin suppresses cell migration and invasion by inhibiting the PI3K-dependent Racl signaling pathway in MDA-MB-231 human breast cancer cells. $J$. Nat. Prod., 77, 1135-1139 (2014).

8) Ikenouchi J, Matsuda M, Furuse M, Tsukita S. Regulation of tight junctions during the epithelium-mesenchyme transition: direct repression of the gene expression of claudins/occludin by Snail. $J$. Cell Sci., 116, 1959-1967 (2003).

9) Kalluri R, Weinberg RA. The basics of epithelial-mesenchymal transition. J. Clin. Invest., 119, 1420-1428 (2009).

10) Ozdamar B, Bose R, Barrios-Rodiles M, Wang HR, Zhang Y, Wrana JL. Regulation of the polarity protein Par6 by TGFbeta receptors controls epithelial cell plasticity. Science, 307, 1603-1609 (2005).

11) Savagner P. The epithelial-mesenchymal transition (EMT) phenomenon. Ann. Oncol., 21 (Suppl. 7), vii89-vii92 (2010).

12) Foerster F, Braig S, Moser C, Kubisch R, Busse J, Wagner E, Schmoeckel E, Mayr D, Schmitt S, Huettel S, Zischka H, Mueller R, Vollmar AM. Targeting the actin cytoskeleton: selective antitumor action via trapping PKCe. Cell Death Dis., 5, e1398 (2014).

13) Higgs HN, Pollard TD. Regulation of actin polymerization by Arp2/3 complex and WASp/Scar proteins. J. Biol. Chem., 274, 32531-32534 (1999).

14) Upadhyaya A, van Oudenaarden A. Actin polymerization: forcing flat faces forward. Curr. Biol., 14, R467-R469 (2004)

15) Yin C, Li H, Zhang B, Liu Y, Lu G, Lu S, Sun L, Qi Y, Li X, Chen W. RAGE-binding S100A8/A9 promotes the migration and invasion of human breast cancer cells through actin polymerization and epithelial-mesenchymal transition. Breast Cancer Res. Treat., 142, 297-309 (2013).

16) Zhang J, Shen Y, Liu J, Wei D. Antimetastatic effect of prodigiosin through inhibition of tumor invasion. Biochem. Pharmacol., 69, 407-414 (2005)

17) Kurisu S, Suetsugu S, Yamazaki D, Yamaguchi H, Takenawa T. Rac-WAVE2 signaling is involved in the invasive and metastatic phenotypes of murine melanoma cells. Oncogene, 24, 1309-1319 (2005).

18) Kurisu S, Takenawa T. The WASP and WAVE family proteins. Genome Biol., 10, 226 (2009).

19) Kurisu S, Takenawa T. WASP and WAVE family proteins: friends or foes in cancer invasion? Cancer Sci., 101, 2093-2104 (2010).

20) Yokotsuka M, Iwaya K, Saito T, Pandiella A, Tsuboi R, Kohno $\mathrm{N}$, Matsubara O, Mukai K. Overexpression of HER2 signaling to WAVE2-Arp2/3 complex activates MMP-independent migration in breast cancer. Breast Cancer Res. Treat., 126, 311-318 (2011).

21) Frugtniet B, Jiang WG, Martin TA. Role of the WASP and WAVE family proteins in breast cancer invasion and metastasis. Breast Cancer: Targets and Therapy, 7, 99-109 (2015).

22) Machesky LM, Insall RH. Scarl and the related Wiskott-Aldrich syndrome protein, WASP, regulate the actin cytoskeleton through the Arp2/3 complex. Curr. Biol., 8, 1347-1356 (1998).

23) Takenawa T, Miki H. WASP and WAVE family proteins: key molecules for rapid rearrangement of cortical actin filaments and cell movement. J. Cell Sci., 114, 1801-1809 (2001).

24) Yarar D, To W, Abo A, Welch MD. The Wiskott-Aldrich syndrome protein directs actin-based motility by stimulating actin nucleation with the Arp2/3 complex. Curr. Biol., 9, 555-558 (1999).

25) Alawin OA, Ahmed RA, Ibrahim BA, Briski KP, Sylvester PW. Antiproliferative effects of gamma-tocotrienol are associated with lipid raft disruption in HER2-positive human breast cancer cells. $J$. Nutr. Biochem., 27, 266-277 (2016).

26) Ayoub NM, Bachawal SV, Sylvester PW. $\gamma$-Tocotrienol inhibits HGF-dependent mitogenesis and Met activation in highly malignant mammary tumour cells. Cell Prolif., 44, 516-526 (2011).

27) Bachawal SV, Wali VB, Sylvester PW. Enhanced antiproliferative and apoptotic response to combined treatment of gamma-tocotrienol with erlotinib or gefitinib in mammary tumor cells. BMC Cancer, 10, 84 (2010).

28) Sylvester PW. Targeting met mediated epithelial-mesenchymal transition in the treatment of breast cancer. Clin. Transl. Med., 3, 30 (2014).

29) Sylvester PW, Ayoub NM. Tocotrienols target PI3K/Akt signaling in anti-breast cancer therapy. Anticancer. Agents Med. Chem., 13, 1039-1047 (2013)

30) Anderson LW, Danielson KG, Hosick HL. New cell line. Epithelial 
cell line and subline established from premalignant mouse mammary tissue. In Vitro, 15, 841-843 (1979).

31) Anderson LW, Danielson KG, Hosick HL. Metastatic potential of hyperplastic alveolar nodule derived mouse mammary tumor cells following intravenous inoculation. Eur. J. Cancer Clin. Oncol., 17, 1001-1008 (1981).

32) Danielson KG, Anderson LW, Hosick HL. Selection and characterization in culture of mammary tumor cells with distinctive growth properties in vivo. Cancer Res., 40, 1812-1819 (1980).

33) McIntyre BS, Briski KP, Gapor A, Sylvester PW. Antiproliferative and apoptotic effects of tocopherols and tocotrienols on preneoplastic and neoplastic mouse mammary epithelial cells. Proc. Soc. Exp. Biol. Med., 224, 292-301 (2000).

34) McIntyre BS, Briski KP, Tirmenstein MA, Fariss MW, Gapor A, Sylvester PW. Antiproliferative and apoptotic effects of tocopherols and tocotrienols on normal mouse mammary epithelial cells. Lipids, 35, 171-180 (2000)

35) Tiwari RV, Parajuli P, Sylvester PW. $\gamma$-Tocotrienol-induced autophagy in malignant mammary cancer cells. Exp. Biol. Med. (Maywood), 239, 33-44 (2014).

36) Parajuli P, Tiwari RV, Sylvester PW. Antiproliferative effects of $\gamma$-tocotrienol are associated with a suppression in c-Myc expression in mammary tumor cells. Cell Prolif., 48, 421-435 (2015).

37) Ayoub NM, Akl MR, Sylvester PW. Combined gamma-tocotrienol and Met inhibitor treatment suppresses mammary cancer cell proliferation, epithelial-to-mesenchymal transition and migration. Cell Prolif., 46, 538-553 (2013).

38) Aggarwal B, Nesaretnam K. Vitamin E tocotrienols: life beyond tocopherols. Genes Nutr., 7, 1 (2012).

39) Sylvester PW, Ak1 MR, Malaviya A, Parajuli P, Ananthula S, Tiwari RV, Ayoub NM. Potential role of tocotrienols in the treatment and prevention of breast cancer. Biofactors, 40, 49-58 (2014).

40) Bachawal SV, Wali VB, Sylvester PW. Combined gamma-tocotrienol and erlotinib/gefitinib treatment suppresses Stat and Akt signaling in murine mammary tumor cells. Anticancer Res., 30, 429-437 (2010).

41) Samant GV, Sylvester PW. $\gamma$-Tocotrienol inhibits ErbB3-dependent PI3K/Akt mitogenic signalling in neoplastic mammary epithelial cells. Cell Prolif., 39, 563-574 (2006).

42) Samant GV, Wali VB, Sylvester PW. Anti-proliferative effects of gamma-tocotrienol on mammary tumour cells are associated with suppression of cell cycle progression. Cell Prolif., 43, 77-83 (2010).

43) Malaviya A, Sylvester PW. Mechanisms mediating the effects of gamma-tocotrienol when used in combination with PPAR $\gamma$ agonists or antagonists on MCF-7 and MDA-MB-231 breast cancer cells. Int. J. Breast Cancer, 2013, 101705 (2013).

44) Shah SJ, Sylvester PW. $\gamma$-Tocotrienol inhibits neoplastic mammary epithelial cell proliferation by decreasing Akt and nuclear factor kappaB activity. Exp. Biol. Med. (Maywood), 230, 235-241 (2005).

45) Wali VB, Sylvester PW. Synergistic antiproliferative effects of gamma-tocotrienol and statin treatment on mammary tumor cells. Lipids, 42, 1113-1123 (2007).

46) Hanna S, El-Sibai M. Signaling networks of Rho GTPases in cell motility. Cell. Signal., 25, 1955-1961 (2013).

47) Nolz JC, Gomez TS, Zhu P, Li S, Medeiros RB, Shimizu Y, Burkhardt JK, Freedman BD, Billadeau DD. The WAVE2 complex regulates actin cytoskeletal reorganization and CRAC-mediated calcium entry during T cell activation. Curr. Biol., 16, 24-34 (2006).

48) Schnelzer A, Prechtel D, Knaus U, Dehne K, Gerhard M, Graeff H, Harbeck N, Schmitt M, Lengyel E. Rac1 in human breast cancer: overexpression, mutation analysis, and characterization of a new isoform, Raclb. Oncogene, 19, 3013-3020 (2000).

49) Zhang Y, Rivera Rosado LA, Moon SY, Zhang B. Silencing of D4GDI inhibits growth and invasive behavior in MDA-MB-231 cells by activation of Rac-dependent p38 and JNK signaling. J. Biol. Chem., 284, 12956-12965 (2009).

50) Fritz G, Just I, Kaina B. Rho GTPases are over-expressed in human tumors. Int. J. Cancer, 81, 682-687 (1999).

51) Iwaya K, Norio K, Mukai K. Coexpression of Arp2 and WAVE2 predicts poor outcome in invasive breast carcinoma. Mod. Pathol., 20, 339-343 (2007).

52) Kikuchi K, Li X, Zheng Y, Takano Y. Invasion of breast cancer cells into collagen matrix requires TGF- $\alpha$ and Cdc42 signaling. FEBS Lett., 585, 286-290 (2011).

53) Fernando HS, Davies SR, Chhabra A, Watkins G, Douglas-Jones A, Kynaston H, Mansel RE, Jiang WG. Expression of the WASP verprolin-homologues (WAVE members) in human breast cancer. Oncology, 73, 376-383 (2007)

54) Morimura S, Takahashi K. Rac1 and Stathmin but not EB1 are required for invasion of breast cancer cells in response to IGF-I. Int. J. Cell Biol., 2011, 615912 (2011). 